\title{
Speed Control of BLDC Motor using Fuzzy: Tuned PID Controller
}

\author{
Jival Angeti \\ Department Electrical and \\ Electronics Engineering \\ Modibbo Adama \\ University of Technology, \\ Yola
}

\author{
Adamu S. Kadalla \\ Department of Electrical \\ and Electronics \\ Engineering \\ Modibbo Adama \\ University of Technology, \\ Yola
}

\author{
Gachada \\ Dubukumah \\ Department of Electrical \\ and Electronics \\ Engineering \\ Modibbo Adama \\ University of Technology, \\ Yola
}

\author{
Bitrus K. Zirata \\ Department of Electrical \\ and Electronics \\ Engineering \\ Adamawa State \\ Polytechnic, Yola
}

\begin{abstract}
Brushless DC (BLDCM) Motor is becoming more prominent and more attractive as the demand for efficiency, reliability, torque control, precise speed and ruggedness increases. BLDC Motor as the name implies they have neither brushes nor commutators, the commutation of BLDC Motor is performed with the help of Electronic circuit, and these Motors have several advantages over Brushed DC Motor which include: better torque versus speed characteristic, higher efficiency, better dynamic response due to low rotor inertia, higher speed range etc. This paper presents the execution of PID controller and Fuzzy Tuned PID controller utilizing Simulink display. Tuning the PID gains and processing utilizing conventional PID controller is troublesome and poor vigorous, it doesn't give fulfilled control characteristic when compare with Fuzzy Tuned PID controller. From the simulation results it is clearly demonstrated that Fuzzy Tuned PID controller gives better control execution when compared with conventional PID controller. MATLAB/SIMULINK environment is utilized to do the examination above.
\end{abstract}

\section{General Terms}

Tuning the PID gain, Commutation sequence, Hall Effect sensor, Fuzzy Logic, Motor, and Speed

\section{Keywords}

BLDC Motor, System Modeling, PID Controller, Fuzzy Tuned PID controller, Speed Control

\section{INTRODUCTION}

Brushless Direct Current (BLDC) Motors are types of Synchronous Motor that are powered by DC source through a power inverter, which generate $\mathrm{AC}$ source for the motor drives [1].The idea of Brushless Direct Current (BLDC) Motors was conceived in 1962 by two Engineers, T.G. Wilson and P.H Trickey. But only became practical in 1980s when permanent magnet materials became readily available by Power Tec Industrial Corporation.[2] These motors are becoming more prominent and attractive as the demand for efficiency, reliability, torque control, precise speed and ruggedness increases. Due to the high torque to volume ratio of BLDCM, they find application in Medical Equipment, Electric Vehicles, Air craft, Home appliances, computers, Robotics, and so on [3]. Recently, high performance BLDC motors are used for variable speed drive system in industries [4]. Brushless, as the name suggests they have neither brushes nor commutators. In regular DC motor, the exchanging of current in the armature coil is achieved with the help of brushes and commutators while in brushless DC motor, the substitution is performed with the assistance of electronic circuit, which decreases mechanical misfortunes and enhances proficiency [2]. In fact, these motors have several advantages over conventional DC motors which include: better torque versus speed characteristic, higher efficiency, better dynamic response due to low rotor inertia, lesser maintenance requirement, low electric noise and high speed rang (up to $10,000 \mathrm{rpm}$ ). Additionally, the proportion of torque conveyed to the size of the motor is higher, making it reasonable in application where space and weight are basic components [5] BLDC motors however, require more complex commutating and control Circuitry and these are the major problems hindering the wide spread application of the motors. For effective use of BLDC motors, it is very necessary to satisfactorily overcome their associated commutation and control problems[6]. Its commutation sequence depends on the exact rotor position which can be obtained using sensor or sensor less techniques[7]. The sensors less technique involves estimation of back electromotive force (Back-EMF) and require extra computation time, high performance processors and large amount of memory. The Sensor based technique on the other hand, uses Hall Effect sensors to decide the position of the rotor at any moment of time [8]. The sensor based technique has proved to be a better candidate for the accurate determination of rotor Position, the major problem left therefore is that of the speed control of the BLDC motor. The control of BLDC Motor has attracted the attention of so many researchers resulting to the development of many control techniques such as Direct Torque Control (DTC), Feedback linearization control, linear quadratic regulator (LQR), Sliding mode control, and so on. In spite of the capability of the cutting edge controllers with alternate structure, Proportional Integral Derivative (PID) type controller is still generally utilized extensively in control of BLDC drive system due to its fast and efficient response [9]. PID controller offers the simplest and yet most efficient solution for many real worlds controls problems so long as the operating point remains fairly constant and its gain appropriately tuned, the problem associated with the PID controller is tuning the gain. In situation where varying operation point is desired, the PID gains must be dynamically updated. Several tuning techniques such as Ziegler-Nichol (ZN), Cohen-Coon, Lambda tuning, Relay Auto tuning and Damped Oscillation have been developed as in[10]. Ziegler-Nichol technique has been very influential but being a trial and error approach, it is time consuming and does not lend itself for online tuning. BLDC Motor being non-linear in nature can easily be affected by the parameter variation and load disturbances[11]. Therefore the proper choice of controller that is robust to 
effectively control its speed gives a better performance by reducing the problem of overshoot, settling time, and oscillation. This paper proposed a fuzzy-tuned PID controller to control a speed of BLDC motor by keeping the motor speed to be constant when the load changes and to demonstrate the dynamic response of the speed.

The simulation results demonstrate that control execution of a Fuzzy tuned PID controller is superior to that of conventional PID controller.

\section{BLDC MOTOR CONSTRUCTION}

BLDC motors shared some similarities with induction motors and brushed DC motors with respect to development and working standards. Much the same as all motors, it has two critical parts: the rotor (rotating part) and the stator (stationary part).The stator magnetic circuit is constructed using steel laminations. Which can be either slotted (inner rotor design) or slotless (outer rotor design) [12] as shown in figure 1. The phase windings are wrapped around the stator, arranged in either - star $(\mathrm{Y})$ or delta $(\Delta)$ patterns. The $\mathrm{Y}$ arrangement gives high torque at low RPM while the $\Delta$ pattern gives low torque at low RPM [13]. The rotor of a BLDC is constructed with permanent magnets consisting of various numbers of poles based on the application, increasing the number of poles gives higher torque however to the detriment of the maximum speed. In an external rotor design, the winding are situated in the focal point of the motor and the rotor magnets encompass the stator winding. However, the rotor magnets act as an insulator, thereby reducing the rate of heat dissipation from the motor. Because of the area of the stator winding, external rotor designs typically operate at lower duty cycles or a lower rated current. In the internal rotor design, the rotor magnets are encompassed by the stator winding which are fastened to the motor's housing. The essential preferred standpoint of an internal rotor development is its capacity to disperse warm which builds its capacity to create torque. For this reason, the majority of BLDC motors use an inner rotor design. Another advantage of an inner rotor design is lower rotor inertia which is a factor for speed control.

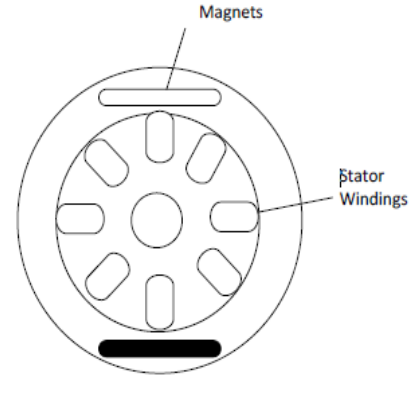

Outer Rotor Design

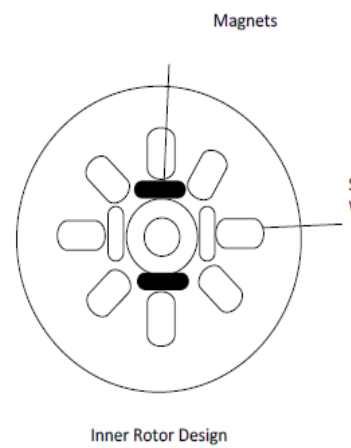

Inner Rotor Design is off). This outcome in six-possible commutation states per revolution. The timing of these high/low arrangements is basic to the rotor operation and requires information of the rotor position in respect to the stator winding

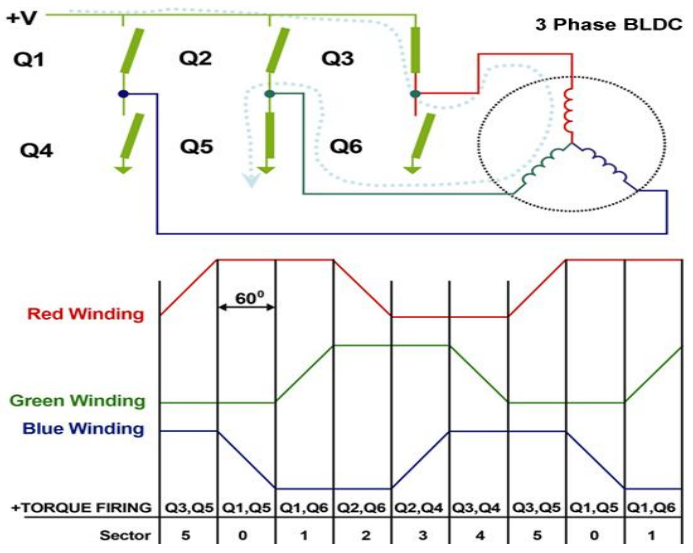

Fig 2: Six-step commutation

The easiest method of detecting the rotor position is Hall Effect sensor. From table 1: HA, HB, and HC represent the Hall sensor signals Q1-Q6 represent the commutation signal. The Hall sensors are kept at 120 degree apart to obtain symmetrical operation of the motor phases. At the point when the rotor position is detected, three piece code of the hall sensor signal is gotten as appeared in table 1 . Each code value determines the rotor position and the relating stator winding that are to be energized. $\mathrm{HA}, \mathrm{HB}$, and $\mathrm{HC}$ signals are high or low contingent upon whether the sensor is close to the North or South Post of the rotor magnets. Based on these signal the switches Q1-Q6 are turn ON/OFF. From table 1 it is seen that when HA and HC are high, the switch Q1 and Q6 conducts and the comparing stator winding are energized. Pulse width Modulation (PWM) signal are produced and speed tracking is accomplished by changing duty cycles

Table 1 Hall Effect Sensor Output

\begin{tabular}{|l|l|l|l|l|l|l|l|l|}
\hline $\mathbf{H}_{\mathbf{A}}$ & $\mathbf{H}_{\mathrm{B}}$ & $\mathbf{H}_{\mathrm{C}}$ & $\mathbf{Q 1}$ & $\mathbf{Q} 2$ & $\mathbf{Q 3}$ & $\mathbf{Q 4}$ & $\mathbf{Q 5}$ & $\mathbf{Q 6}$ \\
\hline 1 & 0 & 1 & 1 & 0 & 0 & 0 & 0 & 1 \\
\hline 1 & 0 & 0 & 1 & 0 & 0 & 0 & 1 & 0 \\
\hline 1 & 1 & 0 & 0 & 0 & 1 & 0 & 1 & 0 \\
\hline 0 & 1 & 0 & 0 & 0 & 1 & 1 & 0 & 0 \\
\hline 0 & 1 & 1 & 0 & 1 & 0 & 1 & 0 & 0 \\
\hline 0 & 0 & 1 & 0 & 1 & 0 & 0 & 0 & 1 \\
\hline
\end{tabular}

Fig 1: Show the BLDCM Outer Rotor and Inner Rotor Design

\section{PRINCIPLE OF OPERATION OF BLDC MOTOR}

BLDC Motor relies on six-step commutation as shown in figure 2 , the results is characterized in trapezoidal shape of the backEMF waveform as also shown in figure 2. In six-step commutation, the three Phase of the BLDC motor are invigorated in 120 degree successions and each winding stay 'high' for 120 degree (see figure 2). Current is gone through two of the three winding whenever one winding held at a high electrical potential and other at a low potential (and the third one

\section{SYSTEM MODELING OF BLDC MOTOR}

BLDC motor can be model mathematically using 3-phase ABC variable, assume that the three-phase BLDC motor is controlled by full-bridge driving in two phase conduction mode. 


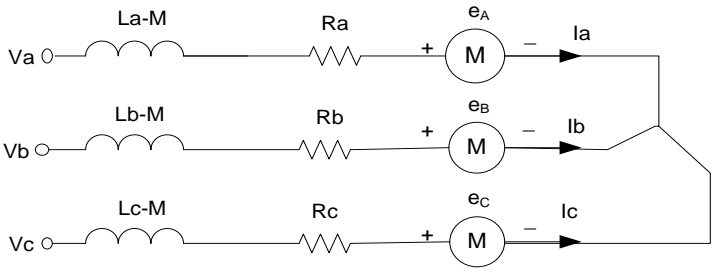

Fig 3: Equivalent circuit of BLDC Motor

The traditional brushed DC Motor has the same mechanism of back-EMF and Electromagnetic torque with that of brushless DC motor, thus similar analysis techniques can be adopted.

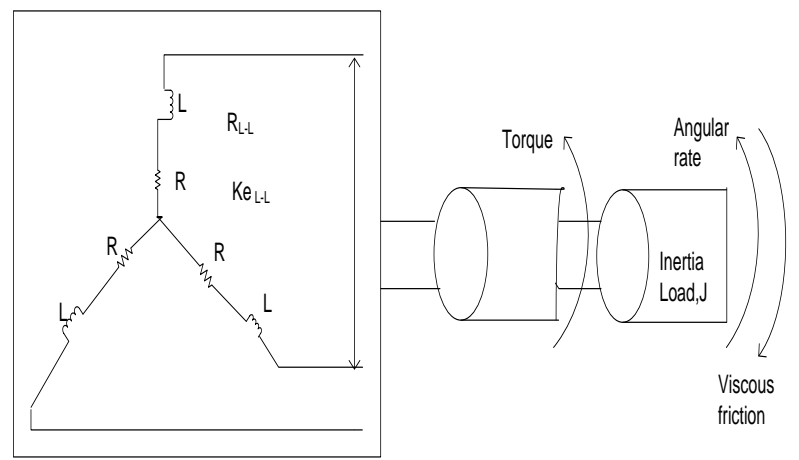

Fig 4: Brushless DC Motor Schematic Circuit

The two phases of the motor excited at any point in time, either $\mathrm{AB}$ or $\mathrm{BC}$ or $\mathrm{CA}$. therefore, the circuit can be simplified as show in fig below.

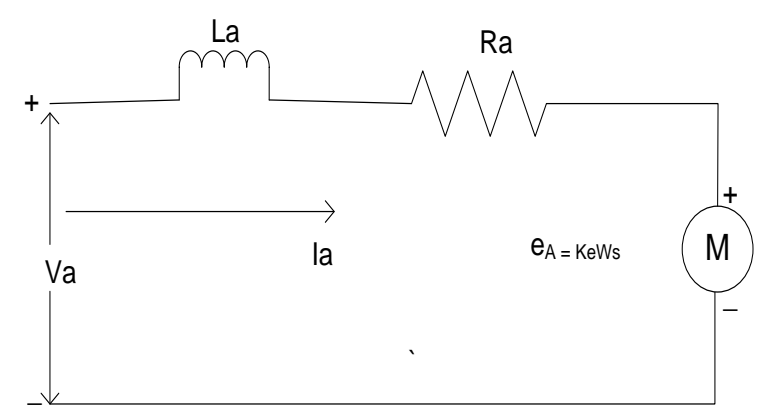

Fig 5: Show the simplified equivalent circuit of the BLDC Motor

Assumed that the motor is picked at rest

$V a-e_{A}=I a R a+L a \frac{d I a}{d t}$

Taken the Laplace transform of equation 1

$V a(s)-e_{A}(s)=\operatorname{RaIa}(s)+\operatorname{sLaIa}(s)$

$\operatorname{RaIa}(s)+s \operatorname{LaI}(s)=V a(s)-e_{A}(s)$

$I a(s)[R a+s L a]=V a(s)-e_{A}(s)$

$I a(s)=\frac{V a(s)-e_{A}(s)}{s L a+R a}$

Since mechanical torque $\mathrm{Tm}$ is proportional to ammature current, that is:

$T_{m}=K_{T} I a$
But for the torque to rotate, it must overcome inertia, friction, and external disturbance. Therefore,

$T_{M}=K_{T} I a=J \frac{d W_{S}}{d t}+F_{k} W_{S}+D$

Assuming the disturbance is zero

$$
\begin{aligned}
& K_{T} I a=J \frac{d W_{S}}{d t}+F_{K} W_{S} \\
& K_{T}\left[\frac{V a(s)-e_{A}(s)}{s L a+R a(s)}\right]=s J W_{S}+F_{K} W_{S}(s)
\end{aligned}
$$

The back EMF is corresponding to the speed of the motor

$e_{A}(s)=K_{e} W_{S}(s)$

Substituting equation (10) into (9)

$K_{T}\left[\frac{V a(s)-K_{e} W_{S}(s)}{s L a+R a}\right]=s J W_{S}(s)+F_{K} W_{S}(s)$

$\frac{K_{T} V a(s)}{s L a+R a}-\frac{K_{T} K_{e} W_{S}(s)}{s L a+R a}=s J W_{S}(s)+F_{k} W_{S}(s)$

$s J W_{S}(s)+F_{K} W_{S}(s)+\frac{K_{T} K_{e} W_{S}}{R a+s L a}=\frac{K_{T} V a(s)}{R a+s L a}$

$W_{S}(s)\left[\frac{(s L a+R a)\left(s J+F_{K}\right)+K_{T} K_{e}}{R a+s L a}\right]=\frac{K_{T} V a(s)}{R a+s L a}$

$\frac{W_{S}(s)}{V a(s)}=\frac{K_{T}}{(s L a+R a)\left(s J+F_{K}\right)+K_{T} K_{e}}$

$\frac{W_{S}(s)}{V a(s)}=\frac{K_{T}}{s^{2} J L a+\left(R a J+L a F_{K}\right) s+\left(R a F_{K} K_{T} K_{e}\right)}$

$G(\mathrm{~s})=\frac{W_{S}(s)}{V a(s)}=\frac{K_{T}}{s^{2} J L a+\left(R a J+L a F_{K}\right) s+\left(R a F_{K} K_{T} K_{e}\right)}$

Where $\mathrm{G}(\mathrm{s})$ is the transfer function of BLDC motor.

$G(\mathrm{~s})=\frac{K_{T}}{s^{2} J L a+\left(R a J+L a F_{K}\right) s+\left(R a F_{K} K_{T} K_{e}\right)}$

Where: $V a=\mathrm{DC}$ source voltage

$e_{A}=$ Phase back-EMF

$R a=$ Line resistance of winding

$R a=2 R$

$L a=$ Equivalent Line inductance of the winding

$L a=2(L a-M)$

$J=$ Rotor moment of Inertia

$W_{S}=$ Rotor Speed

$F_{K}=$ Viscous frictional Coefficient

$K_{e}=$ Coefficient of Line Back-EMF

$K_{T}=$ Coefficient of Line Torque constant 


\subsection{Motor Parameters}

The Electrical Specification used to drive the BLDCM transfer function above is given in the table 2 .

Table 2: Motor Parameters

\begin{tabular}{|l|l|}
\hline BLDCM MODEL & $42 \mathrm{BLFO2}$ \\
\hline Number of poles & 8 \\
\hline Number of phase & 3 \\
\hline Rated Voltage & $24 \mathrm{~V}$ \\
\hline Rated Speed & $3000 \mathrm{rpm}$ \\
\hline $\begin{array}{l}\text { Terminal Resistance Phase } \\
\text { to Phase }\end{array}$ & $1.45 \Omega$ \\
\hline $\begin{array}{l}\text { Terminal Inductance } \\
\text { Phase to Phase }\end{array}$ & $459 \mathrm{mH}$ \\
\hline Peak current & $10.2 \mathrm{~A}$ \\
\hline Torque constant & $0.036 \mathrm{Nm} / \mathrm{A}$ \\
\hline Rotor Inertia & $48 \mathrm{~g} . \mathrm{cm}^{2}$ \\
\hline Peak Torque & $0.38 \mathrm{Nm}$ \\
\hline Back EMF & $3.8 \mathrm{~V} / \mathrm{K}$ \\
\hline
\end{tabular}

\section{SPEED CONTROL TEACHNIQUES}

\subsection{PID Controller}

Fig 6: shows the Simulation Model of the PID controller. The parameters of P, I, D gains, are applied to the Motor.

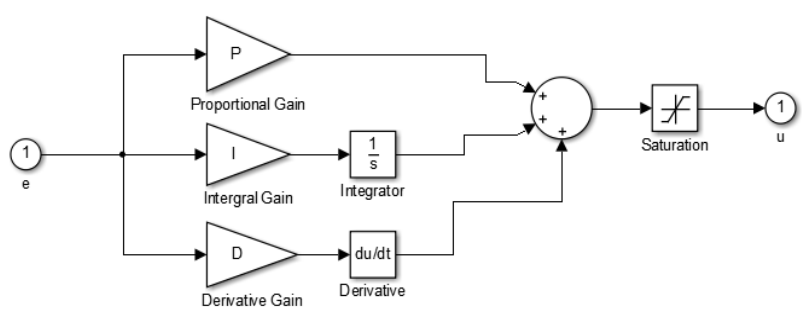

Fig 6: Simulation Model of PID controller

The PID controller is a three -term controller which stands for Proportional (P) Integral (I) and Derivative (D) controls as shown in the diagram above. The controller combines concept of Proportional, Integral and Derivative terms by taken the sum of product of error multiplied by corresponding gains, the output of the PID controller can mathematically express as below.

$u(t)=K_{P} * e(t)+K_{i} \int_{0}^{t} e(t) \mathrm{dT}+K_{d} * \frac{d}{d t} e(t)$

Because of its simplicity, robustness, and excellent performance in many industrial and household applications, in fact most of the industrial drive systems nowadays employ a conventional PID-type controller this is because they works well and yield better transient and steady-state response, if the system parameters stay unaltered amid the working condition. In any case the parameter of the system change during working conditions, However, deviations of such system parameters or load conditions cause the poor performance in a closed-loop system causing larger overshoot, larger rise time, longer settling time and possibly system oscillation. Therefore, the PID controller failed to yield desired result under non-linearity, load disturbance, and parameter variation of the motor and load. Therefore in other to have better system operating condition the parameter of the PID controller need to be tuned appropriately.
This has brought about an expansion of nonlinear controllers that would guaranty on-line tuning of the parameter of the PID.

Table 3. PID Parameters

\begin{tabular}{|l|l|l|l|}
\hline CONTROLLER & $\mathrm{K}_{\mathrm{p}}$ & $\mathrm{K}_{\mathrm{i}}$ & $\mathrm{K}_{\mathrm{d}}$ \\
\hline PID GAINS & 0.0124 & 0.2666 & 0.0002 \\
\hline
\end{tabular}

\subsection{Concept of Fuzzy Logic}

Fuzzy logic is a mathematical environment, based on fuzzy set theory, which admits the degrees of truth or falsehood opposition to "binary logic" that must be either true or false. Fuzzy Logic is an approach that is gaining interest both in the academic world and the industrial fields. Its capability to mimic the human minds makes it a useful scheme for plants experiencing issues with driving scientific models or having execution limitation with classical controllers. Fuzzy logic is multi-valued logic dealing with uncertainty and approximate reasoning [14]. Fuzzy logic control (FLC) deal with rule-base. It algorithm is based on linguistic variable which tries to mimic human's knowledge about how to control a system without requiring a mathematical model.

\section{Structure of a fuzzy controller}

The Fuzzy logic controller controller comprises of four stages as appeared in the figure 7. They are Fuzzification, Rule-based, Inference Engine, and Defuzzification.

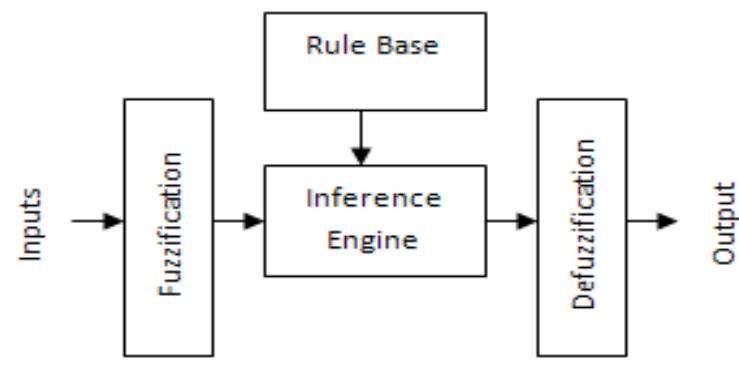

Figure 7: shows the structure of Fuzzy controller.

Fuzzy Membership functions are utilized as a tools used to convert numerical variable to linguistic variable. A fuzzy variable can contain many fuzzy subsets inside, contingent upon what numbers of linguistic terms are utilized. Each fuzzy subset represents one linguistic term. To define fuzzy membership function, the designer pick a wide range of shapes Such as triangle, a trapezoid, etc.[15].

\subsubsection{Fuzzification}

Fuzzy logic utilizes linguistic variables rather than numerical factors. The process of converting a numerical variable into a linguistic variable is called Fuzzification. To perform fuzzy calculation, the sources of info must be changed over from numerical or crisp value into fuzzy variables, and the output should be change From fuzzy variables to crisp value, the fuzzy variables i.e. Error, change in error and output are quantized using the following linguistic terms. Negative large (NL), Negative Small (NS), Zero (ZE), Positive Small (PS), positive Large (PL), positive Very Small (PVS), Positive Small (PS), Positive Medium Small (PMS), Positive Medium Large (PML), Positive Large (PL), Positive Very Large (PVL). 


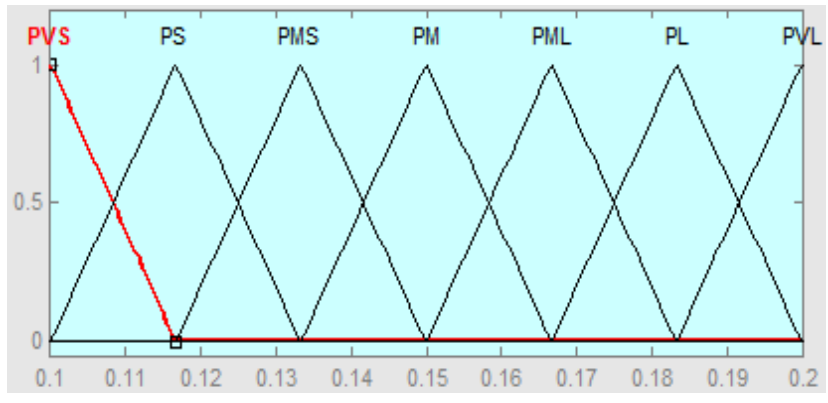

Fig 8: Membership functions for $\left(K_{P}\right.$ and $\left.K_{I}\right)$

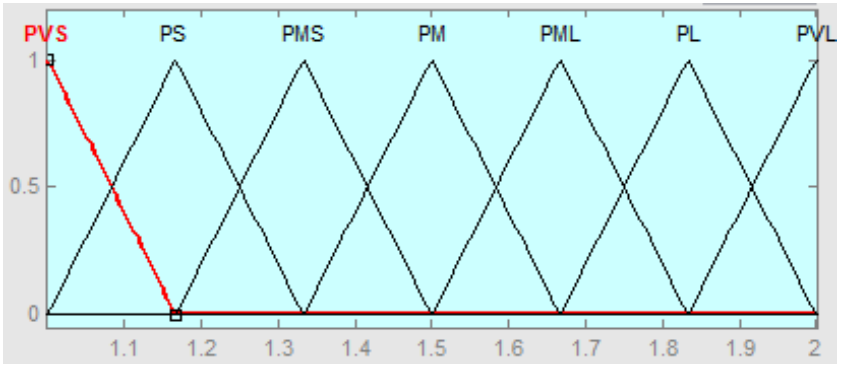

Fig 9: Membership functions for $\left(K_{D}\right)$

\subsubsection{Defuzzification}

Defuzzification is when all the actions that have been activated are combined and Converted into a single non-fuzzy output signal which is the control signal of the system the output levels are depending on the rules that the systems have and the positions depending on the non-linearity existing to the systems [16].

\subsubsection{Rule Base and Inference Engine}

Rather than utilizing a numerical equation, FLC utilizes fuzzy principles to settle on a choice and produce the control activity. The rules are in the form of IF-THEN statements. Inference engine is used to compute the rules generated from the rule base [16]. Fuzzy logic control (FLC) has demonstrated compelling for complex, non-linear and imprecisely characterized forms for which standard model-based control systems are impractical or incomprehensible. Fuzzy logic manages issues that have vagueness, vulnerability and uses membership functions with values varying between 0 and 1 [17]. Recently, a combination of fuzzy logic and PID controller has achieved superior performance as clearly demonstrated by several authors including.[18],[19].This paper proposes fuzzy logic and PID controller for the speed control of a BLDC motor. Fuzzy will be utilized to tune the parameters of PID according to the error and change of error.

\subsection{Fuzzy Tuned PID Controller}

Tuning the gain of a PID controller is extremely significance in PID control. Ziegler and Nichols proposed the outstanding tuning techniques but cannot guaranty better performance for nonlinear system always. Since BLDCM is nonlinear in nature, linear controllers such as PID failed to yield better results. Therefore, fuzzy logic controller is used in this paper to dynamically tune the parameter of the PID during operating condition. The Proportional, Integral and derivative $\left(K_{P}, K_{I}\right.$ and $K_{D}$ ) are the gains of PID controller which, tuned on line to force the system to follow the specified reference point, the structure of fuzzy tuned PID controller is shown in fig.

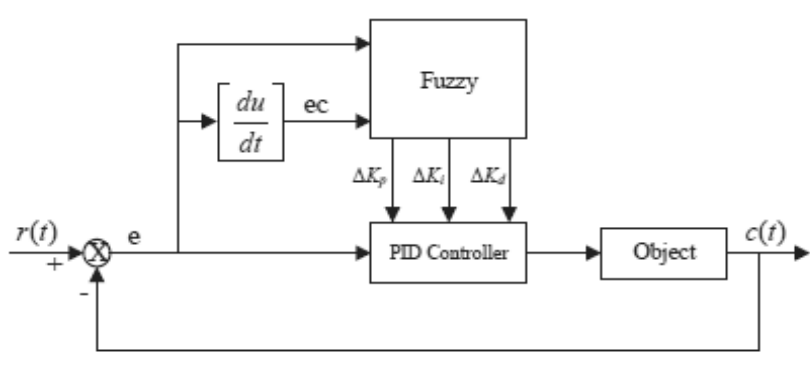

Fig 10: Fuzzy tuned PID controller

Error (E) and change in Error (CE) are the input of Fuzzy, and the three output from Fuzzy controller are KP, KI, and KD. The Fuzzy guidelines are extricated from major learning and human experience about the system. These rules contain the input and output information and yield connections that characterize the control technique. Each control input has seven fuzzy sets so that there are at most 49 fuzzy rules. In this paper the rule base is simplify from 49 to 25 rule base.

Table 4. The Rule Base of $K_{P}$

\begin{tabular}{|c|c|c|c|c|c|}
\hline E/CE & NL & NS & ZE & PS & PL \\
\hline NL & PVL & PVL & PVL & PVL & PVL \\
\hline NS & PML & PML & PS & PL & PVL \\
\hline ZE & PVS & PVS & PS & PMS & PMS \\
\hline PS & PML & PML & PML & PL & PVL \\
\hline PL & PVL & PVL & PVL & PVL & PVL \\
\hline
\end{tabular}

Table 5.The Rule Base of $K_{I}$

\begin{tabular}{|c|c|c|l|c|c|}
\hline E/CE & NL & NS & ZE & PS & PL \\
\hline NL & PM & PM & PM & PM & PM \\
\hline NS & PMS & PMS & PMS & PMS & PMS \\
\hline ZE & PS & PS & PVS & PS & PS \\
\hline PS & PMS & PMS & PMS & PMS & PMS \\
\hline PL & PM & PM & PM & PM & PM \\
\hline
\end{tabular}

Table 6. The Rule Base of $K_{D}$

\begin{tabular}{|c|c|c|c|c|c|}
\hline E/CE & NL & NS & ZE & PS & PL \\
\hline NL & PVS & PMS & PM & PL & PVL \\
\hline NS & PMS & PML & PL & PVL & PVL \\
\hline ZE & PMS & PL & PL & PVL & PVL \\
\hline PS & PML & PVL & PVL & PVL & PVL \\
\hline PL & PVL & PVL & PVL & PVL & PVL \\
\hline
\end{tabular}

Fig 11: show the MATLAB/Simulink Model of Fuzzy Tuned PID controller to control of the Speed of BLDC motor. 


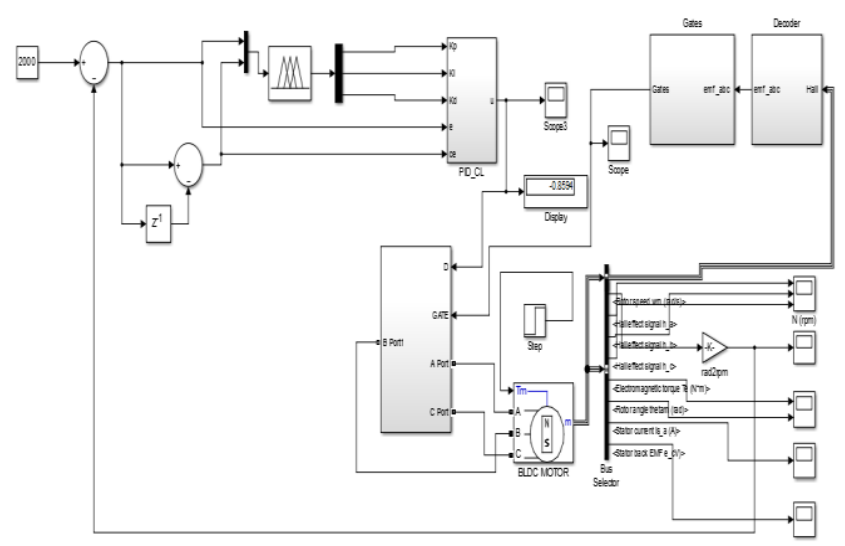

Fig 11: Simulink Model of fuzzy Tuned PID controller

\section{SIMULATION RESULTS}

The Simulation is done for confirming the viability of Fuzzy tuned PID controller, the simulation results were compared with the classical PID controller and found a tangible improvement in the performance characteristic. The speed response of BLDC Motor at 3000 rpm with PID and Fuzzy Tuned PID controller is exhibited in fig 12 to 13 and 14 to 15 separately. Amid running state of BLDC motor, all of a sudden the load of $0.1 \mathrm{Nm}$ is connected during a period of $0.2 \mathrm{sec}$. The controller forces the speed of a motor to a coved level in PID, while in that of FuzzyTuned PID the controller show some level of robustness at a sudden load of $0.1 \mathrm{Nm}$.

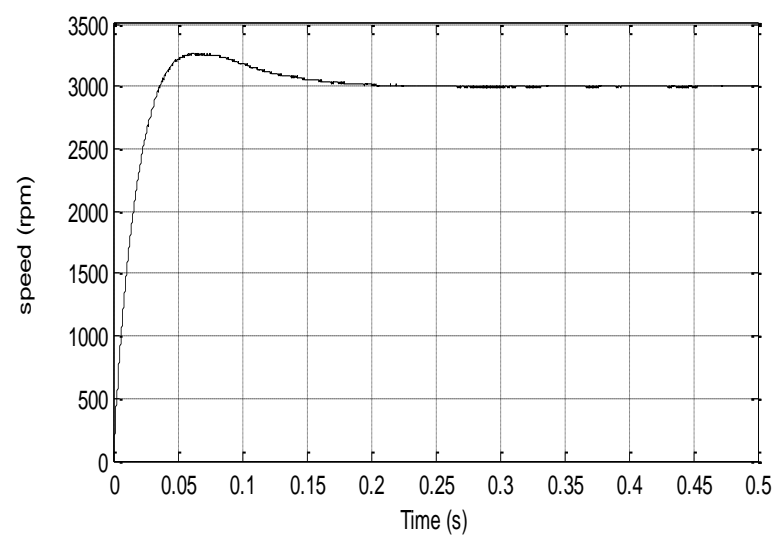

Fig 12: Response of BLDCM using PID on No-load

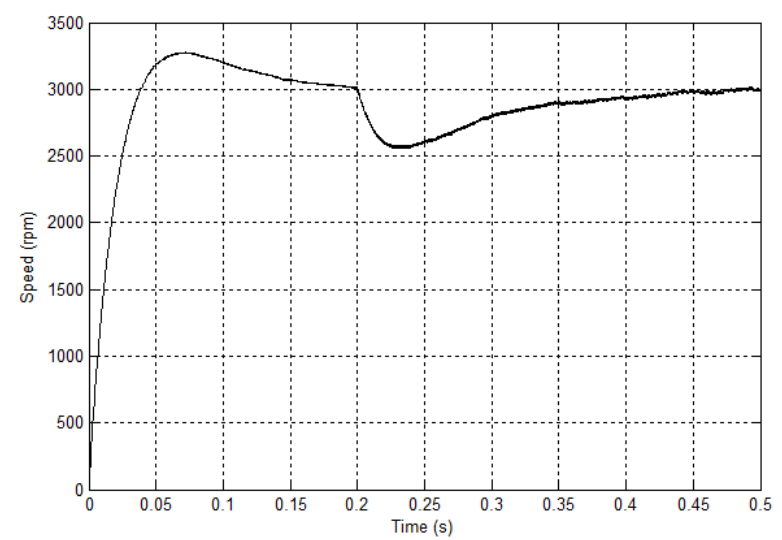

Fig 13: Response of BLDCM using PID controller on Sudden Load of $0.1 \mathrm{Nm}$ at a period of $0.2 \mathrm{sec}$

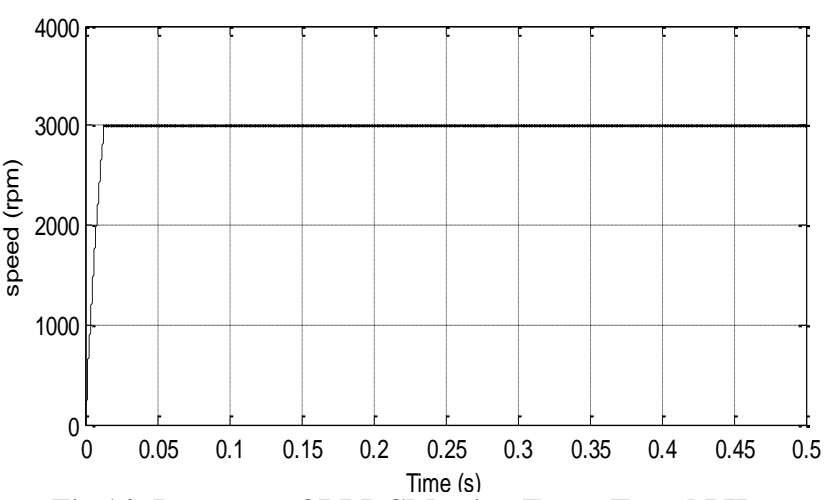

Fig 14: Response of BLDCM using Fuzzy Tuned PID controller on no-load

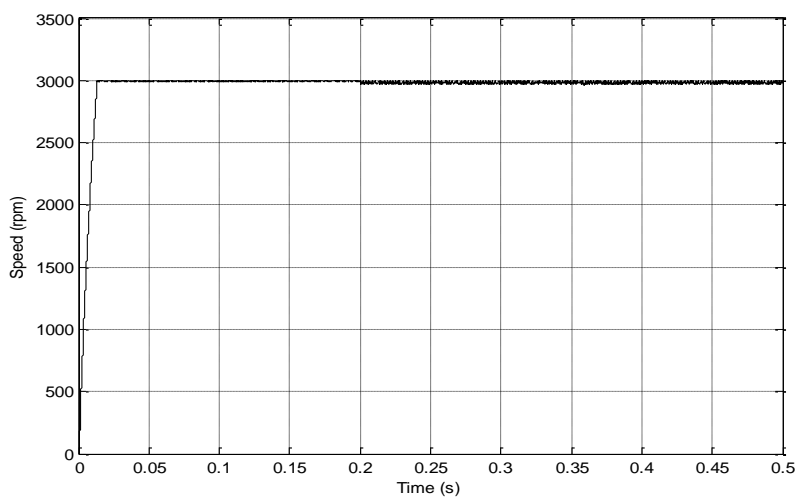

Fig 15: Response of BLDCM using Fuzzy Tuned PID Controller on Sudden load of $0.1 \mathrm{Nm}$ at a period of $0.2 \mathrm{sec}$.

Table 7: Performance Result for PID and Fuzzy tuned PID controller

\begin{tabular}{|c|c|c|}
\hline PARAMETER & $\begin{array}{c}\text { PID } \\
\text { CONTROLLER }\end{array}$ & $\begin{array}{l}\text { FUZZY TUNED } \\
\text { PID } \\
\text { CONTROLLER }\end{array}$ \\
\hline $\begin{array}{c}\text { Rise Time }\left(T_{R}\right) \\
(\mathrm{sec})\end{array}$ & 0.0368 & 0.0139 \\
\hline $\begin{array}{c}\text { Settling Time }\left(\mathrm{T}_{\mathrm{S}}\right) \\
(\mathrm{sec})\end{array}$ & 0.3995 & 0.07036 \\
\hline $\begin{array}{c}\text { Maximun } \\
\text { Overshoot }\left(M_{0}\right) \\
\left(r_{p m}\right)\end{array}$ & 255 & 0 \\
\hline Stability & Good & Very Good \\
\hline
\end{tabular}

\section{CONCLUSION}

This paper demonstrate the speed control of a three phase BLDC motor drive system utilizing ordinary PID and Fuzzy tuned PID controller.The control conspire was modeled and designed in MATLAB SIMULINK and the simulation result was assessed.Base on the simulation results, the execution of the two controller are analyzed on the premise of different control system parameters, for example, maximun overshoot, rise time and settling time. It is clearly shown that for the same operating conditions the control concept using Fuzzy tuned PID controller has better speed regulation and disturbance rejection than the conventional PID controller.

\section{REFERENCES}

[1] N. N. Baharudin and S. M. Ayob, "Brushless DC Motor Drive Control Using Single Input Fuzzy PI Controller (SIFPIC)," IEEE Trans. 2015. 2015., 2015. 
[2] P. Sajitha and A. M. Jashper, "Direct Torque Control of a Bldc motor based on Computing Technique," IOSR J. Electr. Electron. Eng., vol. 6, no. 6, pp. 01-08, 2013.

[3] P. Yedamale, "Brushless DC motor Fundamentals," 2003.

[4] R Arulmozhiyal, "Desing and Implementation of Fuzzy PID Controller for BLDC Motor Using FPGA," 2012 IEEE Int. Conf. Power Electron. Drives Energy Syst., vol. 12, 2012.

[5] P. Yedamale, "Brushless DC Motor Control Using PIC18FXX31 MCUs," pp. 1-26, 2004.

[6] M. A. Shamseldin and A. A. El-samahy, "speed control of BLDC motor by using PID control and self-tuning Fuzzy PID controller," 15th Int. Work. Res. Educ. Mechatron., vol. 6, no. 14, pp. 978-1-4799-3029, 2014.

[7] J. C. Gamazo-Real, E. Vázquez-Sánchez, and Jaime Gómez-Gil, "Position and Speed Control of Brushless DC Motors Using Sensorless Techniques and Application Trends," Sensors, no. 10, pp. 6901-6947, 2010.

[8] S. B. Ozturk, W. C. Alexander, and H. A. Toliyat, "Direct Torque Control of Four-Switch Brushless DC Motor with Non sinusoidal Back-EMF," IEEE Trans Power Electron., vol. 25, no. 2, pp. 263-271, 2010.

[9] C. Lin, H. Jan, and N. Shieh, "GA-based multiobjective PID control for a linear brushless DC motor," IEEE/ASME Trans. Mechatronics, vol. 8, pp. 56-65, 2003.

[10] P. Cominos and N. Munro, "PID controllers: recent tuning methods and design to specification," IEE proceedings,Control Theory Appl., pp. 46-53., 2002.
[11] H. Mohan, K. P. Remya, and S. Gomathy, "Speed Control of Brushless DC Motor Using Fuzzy Based Controllers," Int. Res. J. Eng. Technol., vol. 02, no. 04, 2015.

[12] R. Gambhir and A. K. Jha, "Brushless DC Motor?: Construction and Applications," Int. J. Eng. Sci, vol. 2, no. 5, pp. 72-77, 2013.

[13] J. W. Nilsson and S. Riedel, Electric Circuits, vol. 8. 2009, p. 50.

[14] S. K. Lakhanwal and A. Gill, "Fuzzy logic Technique Based Speed Control of a Permanent Magnet Brushless DC Motor Drive," Int. J. Mod. Eng. Res., vol. 4, no. 8, pp. 112, 2014.

[15] A. A. Zanjade and J. W. Bakal, "Hardware / Software Implementation of Fuzzy - Neural - Network Self Learning Control Methods for Brushless DC Motor Drives,” Int. J. Eng. Res. Technol., vol. 2, no. 4, pp. 717720, 2015.

[16] A. A. Zanjade and J. W. Bakal, "Hardware Implementation of Fuzzy Logic Controller for Sensorless Permanent BLDC Motor Drives," Int. J. Eng. Res. Technol., vol. 2, no. 4, pp. 717-722, 2013.

[17] Z. K. and S. Bogdan, "Fuzzy Controller design Theory and Applications," 2012 7th IEEE Conf. Ind. Electron. Appl., 2012.

[18] M. A. Shamseldin and A. A. El-samahy, "Speed Control of BLDC Motor By Using PID Control and Self-tuning Fuzzy PID Controller," 15th Int. Work. Res. Educ. Mechatron., 2014.

[19] R. Kandiban and R.Arulmozhiyal, "Design of Adaptive Fuzzy PID Controller for Speed control of BLDC Motor," Int. J. Soft Comput. Eng., vol. 2, no. 1386-390, 2012. 